\title{
Evidence Based Forensic Medicine: Roadmap to Enhance Teaching Horizon
}

ISSN: 2578-0042

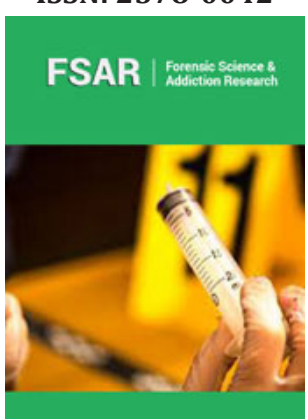

*Corresponding author: Pragnesh B Parmar, Associate Professor, Department of Forensic Medicine, Gujarat, India

Submission: 留 June 11, 2019

Published: 侮June 26, 2019

Volume 4 - Issue 5

How to cite this article: Pragnesh B Parmar. Evidence Based Forensic Medicine: Roadmap to Enhance Teaching Horizon. Forensic Sci Add Res. 4(5). FSAR.000605.2019.

DOI: 10.31031/FSAR.2019.04.000605

Copyright@Pragnesh B Parmar, This article is distributed under the terms of the Creative Commons Attribution 4.0 International License, which permits unrestricted use and redistribution provided that the original author and source are credited.

\author{
Pragnesh B Parmar* \\ Department of Forensic Medicine, India
}

\section{Introduction}

The primary aim of education is to develop professionals who are capable of doing innovative things and not just repeating past methods blindly. They must go beyond the past generations have done; via evidence-based education which make them creative, inventive, and ready to discoverers, which can be critical and verify, and they must not accept everything they are offered [1]. The innovative way of teaching which is aimed at incorporating skills of gathering and generating evidence, ability to critically appraise, analyze and apply in the right context is named 'evidence based practice' (EBP) and incorporation of same principle in all aspects of teaching and learning process to impart the process more perfect is Evidence Based Education System (EBES) [1]. In present context, technology and science has made it possible to access information about researches immediately after publication via internet, much before they find a place in the textbook. Millions of data with flooding of information are available on internet but to choose right one from them is an art of prudent health professional [1,2]. Evidence Based Forensic Medicine (EBFM) is providing platform to create Indian Medical Graduate (IMG) to be competent enough to choose right evidence according to need and develop lifelong learning potential for continuous professional development.

\section{Concept of EBM}

The term Evidence Based Medicine (EBM) is coined by Gordon Guyutt and then after many subjects in medical and paramedical field followed the same concept. Evidence Based Forensic Medicine (EBFM) can be possible to practice as innovation in medical education. All over the world now, hospital administrators, academicians, and clinicians consider this as a high order of need for medical practice. The whole concept of EBM is based on evidence [3]. Formulation of PICO based study design and choosing right comparator may be perplexing in such interventions [3]. The ultimate beneficiaries of EBFM are patients [4,5], who would reap the rewards of better care. Authors have stated that EBM aids in clinical decision making in all fields of medicine, including primary care [6,7].

\section{Aim of EBFM}

A. To prepare and train the undergraduate and post graduate students to be able to access the best contemporary evidence on any matter under consideration.

B. To be able to appraise, analyze and apply evidence according to need.

C. To initiate, implement and assess the best methods of teaching and learning, as supported by recent evidences in all the academic activities of the subject [1,2].

\section{Stages of implementation of EBFM}

Stage 1: Infrastructure up gradation: Basic requirement to practice EBFM is to make entire college campus Wi-Fi enabled with facility of computer or laptops to each and every faculty and students.

Stage 2: Faculty training programs: Every faculty must be trained in concept of Evidence Based Practice (EBP) with hands on practice of various topics like search engine, search filters, what is evidence, how to search for it, how to appraise, analyze and apply it, core concepts of EBM, traditional vs knowledge generating evidence, etc. 
Stage 3: Learning resource materials: College and Departmental library must be equipped with subscription of internationally accepted, reputed databases like Pubmed, Scopus, Web of Science etc. with free access to both students and teachers along with subscription of various journals and books.

Stage 4: Teaching - learning methods: Small group inter active evidence-based tutorials, evidence-based seminars, journal club, role modelling, peer teaching, projects etc. must be implemented.

Stage 5: Reform of evaluation methods: Along with formative and summative evaluation, concept of daily evaluation, 360-degree feedback can be adopted. Traditional practical can be replaced by OSPE (Objectively Structured Practical Examination). Internet based learning must be encouraged.

Stage 6: Periodic evaluation of curriculum: Evidence based curriculum must be designed with implementation of all above stages and it must be reforming every year via feedback of students, alumni, teachers and experts [2].

Forensic Medicine can be made evidence based with incorporation of various innovative things. All students can be taught regarding various aspect of evidence-based practice like what is evidence, how to search for it via various search engines and search filters, how to appraise, analyze and apply evidence, what is PICO format and how to use it, etc.

\section{Conclusion}

Structure and concept framed here for evidence based education is just the beginning and primary phase and there is a lot left to be done for future improvement, there is a long ways to go which is not possible overnight but it requires lot of support and encouragement to implement it and analyze it for better tomorrow.

\section{References}

1. http://www.sumandeepuniversity.co.in/index.php?option=com_ content\&view=article\&id=118\&Itemid=570\&lang=en .

2. http://www.sumandeepuniversity.co.in/index.php?option=com content\&view=article\&id=119\&Itemid=571\&lang=en.

3. Lakhani JD, Muley A (2014) Generating Evidence. JIHS 2(1): 1-2.

4. Jacobson C, Edwards A, Granier S, Butler C (1997) Evidence-based medicine and general practice. British Journal of General Practice 47(420): 449-452.

5. McCoU A, Smith H, White P, Field J (1998) General practitioners perceptions of the route to evidence-based medicine: a questionnaire survey. BMJ 316(7128): 361-365.

6. Richardson WS, Wilson MC, Nishikawa J, Hayward RS (1995) The wellbuilt clinical question: a key to evidence-based decisions. ACP J Club 123(3): A12-13.

7. Jadad AR, Haynes RB (1998) The Cochrane Collaboration - advances and challenges in improving evidence-based decision making. Med Decis Making 18(1): 2-9. 